Purpose and pleasure in late life: conceptualising older women's participation in art and craft activities

Jeannine L.M. Liddle ${ }^{\mathrm{a}}$

Lynne Parkinson ${ }^{\mathrm{a}, \mathrm{b}}$

David W. Sibbritt ${ }^{\mathrm{a}, \mathrm{c}}$

${ }^{\mathrm{a}}$ Research Centre for Gender, Health and Ageing, School of Medicine and Public

Health, Faculty of Health, The University of Newcastle, Callaghan NSW 2308,

Australia

${ }^{\mathrm{b}}$ HEALTH Collaborative Research Network and Institute for Health and Social

Sciences Research, CQUniversity, Bruce Highway, Rockhampton, QLD 4702,

Australia, email: 1.parkinson@cqu.edu.au

${ }^{\text {c }}$ Faculty of Health, University of Technology Sydney, 235-253 Jones Street, Ultimo,

NSW 2007, Australia, email: david.sibbritt@uts.edu.au

Corresponding author: Dr Jeannine Liddle, email: jeannine.liddle@uon.edu.au

Tel (c/o): +61 240420669 Fax: +61 240420044

Suggested running title: Purpose and pleasure in late life 


\title{
Purpose and pleasure in late life: conceptualising older women's participation in art and craft activities
}

\begin{abstract}
The fourth age, as the last stage of life, represents a final challenge to find personal meaning in the face of changing capacities, illness and disability. Participation in valued activities is important for sustaining interest in life and has been associated with enhanced health and well-being. Art and craft activities are a popular form of participation among women in late life with growing international interest in the potential for these types of activities to maintain health and well-being and address problems of social isolation. Drawing on open text comments from 114 women enrolled in the Australian Longitudinal Study on Women's Health and in-depth interviews with 23 women all aged in their eighties, this paper explores the nature of older women's participation in art and craft activities and conceptualises links between participation in these activities and health and well-being in late life. Participation in art and craft activities is complex and dynamic, comprising cognitive and physical processes infused with emotion and occurs in the context of social relationships, physical spaces, physical ailments and beliefs about the value of the activities. By participating in art and craft activities, older women find purpose in their lives, contributing to their own psychological well-being while helping and being appreciated by others. They develop a self view as enabled and as such take on new art and craft challenges, continue to learn and develop as art and craft makers and remain open to new possibilities.
\end{abstract}

Key words - fourth age, arts participation, women, theory development 


\section{Introduction}

If a third age of human lifespan has been envisioned as a time of choice, growth and opportunity, a fourth age, by contrast, has been viewed as a time of lost choice, decline and difficulty (Lloyd, Calnan, Cameron, Seymour and Smith, 2012). However, an exact age-range for the fourth age is not agreed. In developed countries, definitions based on population demographics would put the start of the fourth age at around 75 - 85 years (Baltes and Smith, 2003). At this stage, the collective efforts of society in general, science and medicine, governments and individuals, appear less able to maintain or improve quality of life (Baltes and Smith, 2003). International policies that encourage active participation with the aim to create inclusive societies where older adults can lead full and independent lives (United Nations, 2008) may be orientated more to adults in the third age than the fourth, and inadvertently create a new form of ageism where more dependent older adults are discriminated against for not conforming to an unrealistic ideal (Boudiny, 2012). Rather, recognising the diversity of ageing allows active engagement in life in many forms regardless of age or dependency (Boudiny, 2012).

The concept of ageing well in late life continues to evolve. Health professionals and researchers have traditionally taken a biomedical approach emphasising the absence of chronic disease or physical disability (Depp and Jeste, 2006; Glatt, Chayavichitsilp, Depp, Schork and Jeste, 2007). Increasingly, the importance of "behavioural and emotional plasticity” (Glatt et al., 2007, p.291) that facilitate coping strategies appropriate to the “challenges of the later years” (Crosnoe and Elder Jr., 2002, p.324) is being highlighted. Doing something meaningful and having a positive attitude to life are attributes that older people themselves value in the context of ageing well and 
these attributes can occur in the presence of chronic disease and physical disability (Glatt et al., 2007; Montross et al., 2006). Older people consider ageing well as a multidimensional construct incorporating physical, functional, psychological and social aspects (Phelan, Anderson, LaCroix and Larson, 2004) and in regard to the ageing process represents a "level of health and adaptation ... acceptable to the individual” (Bryant, Corbett and Kutner, 2001, p.928).

Despite much evidence in the empirical literature showing links between older people's activity participation and their health, well-being and/or survival, theoretical understandings for why these associations occur continue to be refined (Adams, Leibbrandt and Moon, 2011). Activity theory drove much of the early work (Lemon, Bengston and Peterson, 1972) the main premise of which is that activities offer roles which contribute to an older person's identity and sense of self in relation to others leading to greater satisfaction with life. More recently, the theory of Selective Optimization with Adaptation has proposed that in the face of changing conditions and capacities (as per the fourth age), compensatory strategies are prioritised to maintain the most meaningful activities (Baltes and Baltes, 1990). A narrower range of activities allows more time and energy to be focused on the specific activities that matter most to the individual.

In the developed world, people aged in their eighties and older make up the fastest growing segment of the population (World Health Organization, 2002). Women significantly outnumber men in this age group (Australian Bureau of Statistics, 2006) and are the focus of the current study. Art and craft activities, as a form of activity participation, are popular among older women (Women’s Health Australia, 2011). Art 
and craft activities refer to any visual art or craft practices which aim to produce tangible items regardless of the level of expertise (Reynolds and Lim, 2007). Studies conducted in Australia (Women's Health Australia, 2011), Sweden (Agahi and Parker, 2008; Häggblom-Kronlöf and Sonn, 2005; Silverstein and Parker, 2002) and North America (Hughes, Chang, Vander Bilt and Ganguli, 2010; Menec, 2003) have estimated that between one quarter and over half of older women are involved in hobbies or handiwork like sewing, knitting or woodworking. There has been growing international interest in the potential of art-making activities to improve health and well-being and address problems of social isolation among older people (Greaves and Farbus, 2006; Hacking, Secker, Kent, Shenton and Spandler, 2006; Stickley and Duncan, 2007). While health-oriented research has considered links between creative activity and ageing well for some time (Adams-Price, 1998) arts-oriented research in the context of health, is at an early stage in terms of both theory development and empirical studies (Burt and Atkinson, 2012; Galloway, 2006; Putland, 2008; Wreford, 2010). Specifically, Raw, Lewis, Russell and Macnaughton (2012) consider there is a fundamental lack of theoretical understanding about art-making practice especially in the community setting, and argue that such understanding is vital as a basis for ongoing empirical work. Others in the field of arts and health have similarly urged for theory development around the "complex relationships and transmission mechanisms between creativity, self-expression and health” (O'Shea and Léime, 2012, p.869).

To date, art-making activities are theorised as offering benefits to psychological health through the experience of flow states where the individual, freed from selfconsciousness, becomes completely absorbed in an activity where challenge is optimally matched to skill (Csikszentmihalyi, 1996). Peak experiences can occur in the act of making art and craft items and involve altered perception and sense of 
being. The individual achieves a unified sense of self where potential capacities and talents intrinsic to the person's own nature are made real (Maslow, 1968, 1976). Psycho-biological theories of art refer to cortical arousal where in making art, the brain is stimulated by novel, complex, incongruous and ambiguous components and this arousal is experienced as pleasure (Runco, 2007). Art-making is seen as a deeply human trait which facilitates "socially important behaviour” where "group values often of a sacred or spiritual nature” are shared (Dissanayake, 1988, p.167). Artmakers embody care in the artistic object and, by showing care, enhance social connections between themselves and others (Dissanayake, 1988). A sense of belonging to a social world outside the self is also a feature of the concept of generativity where individuals, through art-making activities, may seek to nurture and guide the next generation, contribute to society and leave a legacy (Cheek and Piercy, 2004; Piercy and Cheek, 2004; Schofield-Tomschin and Littrell, 2001).

Previous qualitative studies have identified benefits from art and craft participation as including a sense of identity (Dickie, 2003; Howie, Coulter and Feldman, 2004; Johnson and Wilson, 2005; Reynolds, 2009), enhanced mood (Adamson and Parker, 2006; Forssén, 2007), self-development (Dickie, 2003), and formation/deepening of relationships which provide support in times of difficulty (Cheek and Piercy, 2004; Piercy and Cheek, 2004). However, a specific focus on late life was lacking in these studies, as was substantive theory. One study which did include adults aged up to 93 years found that visual fine-arts participation contributed to a "sense of competence, purpose, and growth” as well as developing problem solving skills which could be applied to other areas of life (Fisher and Specht, 1999, p.457). Another study involving women aged 60-86 years noted that visual art-making was an activity which 
enriched the "inner life” (Reynolds, 2010, p.139) as well as allowing women to connect with others. Both elements - "looking inwards" and "looking outwards” contributed to well-being (Reynolds, 2010, p.139).

This paper sets out a qualitative study which aimed to explore the nature of older women's participation in art and craft activities and conceptualise links between participation in these activities and health and well-being in late life. As such, the study aimed to extend existing conceptualisations of participation by women in late life as well as theoretical understandings of how participation in art-making activities may specifically relate to health and well-being - areas of theoretical enquiry which are currently underdeveloped.

\section{Methods}

\section{Data collection}

The Australian Longitudinal Study on Women’s Health (ALSWH) is a nationally representative study which aims to investigate multiple factors affecting the health and well-being of women over a 20 year period (Women's Health Australia, 2011). Regular postal surveys have been conducted since $1996(n=12,939)$ with a cohort of women born between 1921 and 1926. In the current study, two distinct sources of data were drawn upon - firstly, all open text comments that referred to art and craft activities in response to the final question in the 2005 and 2008 surveys which asked survey participants to write "anything else you would like to tell us about changes in your health” (Women's Health Australia, 2011). Secondly, women were purposively recruited to participate in a 30-60 minute in-depth telephone interview in 2010/2011 based on their self-reported participation in art and craft activities such as handiwork 
or painting pictures at the time of the 2008 survey. The interviews explored the women's past and present involvement in art and craft activities, processes of making, interactions with others through art and craft making, motivations for art and craft making, and perceived relationships between these activities and health and wellbeing. An interview guide was used containing core questions and script with flexibility to ask prompt and follow up questions as needed. Interviews were conducted and audio-recorded by the first author and then transcribed verbatim. Immediately following each interview, the first author documented her reflections on the interview content and conduct as well as emerging ideas which informed subsequent interviews. All interview participants were given the opportunity to review and if necessary edit and add to their individual transcripts. Sixteen women took up this offer, with four women providing additional comments and clarifications which were of a minor nature. Preliminary analysis focused on the open text comments in order to identify major gaps in information that would then be addressed in the interviews. For example, the open text comments provided minimal information on physical environments. This gap was then addressed through specific questioning in the interviews. Subsequently, the open text comments and interview transcripts were combined into the one dataset and considered as a whole for the analysis.

\section{Data analysis}

Data analysis was informed by techniques of Grounded Theory (Corbin and Strauss, 2008; Morse et al., 2009). The open text comments and interview transcripts were read and re-read multiple times. Conceptual labels or codes were applied to segments of data. Working hypotheses were developed through strategies of analytic questioning and the construction of diagrams which "depict relationships between 
analytic concepts” (Corbin and Strauss, 2008, p.117). Constant comparison was made between the data and emerging concepts, with the analysis iteratively shifting back and forth between the source data and conceptual interpretations of the data. The writing of memoranda formed part of the analytic process by documenting the thinking behind the abstraction of source data into concepts, how concepts were interrelated and how the final conceptual model was determined.

The study was approved by the University of Newcastle Human Research Ethics Committee and the ALSWH Publications, Substudies and Analyses Committee.

\section{Findings}

\section{Study participants}

Relevant comments from the ALSWH 2005 and 2008 surveys were identified from 114 women, while 23 women participated in the interviews. Study participants (from both data sources combined) ranged in age from 80 - 89 years; came from a mix of urban and rural locations across Australia and had a range of educational backgrounds. They participated in a variety of art and craft activities including knitting, crochet, needlework, spinning and weaving, painting, pottery, photography and crafts such as card or jewellery making.

\section{The act of making}

Making an art or craft item was a focused and purposeful act which involved thought, the bodily senses of vision and touch, and the physical manipulation of tools and materials. The act of making was cognitively demanding and required skills in 
planning, evaluation, counting, measurement and problem solving. Concentration was required especially for complex processes:

“With cross-stitching I work from graphs and you're counting all the time and changing colours all the time, so that your brain has to be active at all times”.

“To do anything like that, embroidery, knitting, sewing, you need to be quiet on your own so that you can concentrate on what you're doing”.

Vision and touch were essential requirements for the act of making. Patterns and colour were closely observed, including forms from nature and the surrounding environment. The sensual aspect of handling materials or responding to particular aesthetic effects was also noted:

“I think oil has such depth and it's a very sensuous medium. It's very alive and its colours are beautiful”.

Coordination of eye with hand enabled the manipulation of tools and materials. Machinery such as knitting machines or weaving looms involved not only the eyes and hands but the feet or whole body. Physical as well as cognitive demands of operating these types of equipment were recognised:

"Weaving is quite physical as well as mental because you have to be active all the time”.

In the act of making, a range of emotions were experienced such as feeling frustrated or impatient, absorbed, calm and relaxed, satisfied, having fun, being excited. 
However, the predominant emotion described was pleasure and this was a motivator for ongoing involvement in the activity:

“I get a lot of pleasure and enjoyment out of it (painting). I wouldn’t be doing it otherwise".

\section{Contexts of participation in art and craft activities}

The core element of participation was the act of making itself. However, the act of making was intimately related to contexts of participation, particularly the social context, the physical spaces in which participation occurred, and the individual's physical ailments and beliefs about the value of participation to her own health and well-being. These contexts facilitated or hindered participation to varying degrees. Decisions to begin and/or continue a particular art and craft activity were influenced by family, friends, opportunities to learn necessary skills, availability of transport, and financial resources. For example, husbands assisted participation by helping with household chores like cooking, buying or repairing equipment, framing items made or doing home modifications to make more space for the activity. Friends encouraged participation in new art and craft activities and prompted continuing effort through a shared interest:

"I have a friend who cross-stitches too. In fact we both started with the same thing because we both bought the same magazine and we both decided to give it a go and we used to compete with each other. She would finish something and she'd bring it and show me and I'd finish something and show her and we'd “ooh” and “ahh” and carry on like a couple of twits”. 
“There’s a group of us and we meet together every Monday morning.

Whatever happens I always gather myself up and go. Sometimes I don’t do a lot of painting when I'm out in the group. I do more when I come home”.

Art and craft activities were also a means of making friends especially when moving to new areas:

"When we came up here to live, my husband found something else he could do here and I was on my own a lot, so I found it (painting group) was a wonderful outlet to go and meet people”.

Having like interests and attitudes contributed to a shared sense of artistic identity and connection with others:

"You find sharing anything with anybody else, if they are looking and can see something in it as well as you, you feel that you're not alone. There's that sense that you know other photographers and you all have, not the same eyes exactly, but the same feeling about it”.

As well as fostering social connections with other individuals, art and craft participation fostered connections at an organisational level. Community organisations provided opportunities for education and training; access to reference books and magazines, materials and equipment; competitions; venues for where activities were undertaken; venues for where work was exhibited and/or sold; and markets for finished products (profit and not-for-profit). 
As materials, equipment and finished items occupied space, the amount of physical space available had a bearing on the extent to which art and craft activities occurred. Where women lived with other people, they had to negotiate this space with others. Downsizing from larger homes to smaller ones had also necessitated selling or giving away materials and equipment and in some cases giving up art and craft activities. One woman who had moved into a hostel said:

"I’ve sold my looms because it was too difficult here. When I put a warp on a loom, I put a good long one on because it takes a long time to put a warp on and there aren’t facilities here to have warps hanging around the rooms”.

All women interviewed did art and craft activities at home and of these, more than half (14) did art and craft activities in venues outside the home. Difficulties were encountered attending these venues if the woman was unable to drive or be driven to the activity, or where public transport or taxis were unsuitable, unavailable or unaffordable.

Physical ailments, especially visual problems and forms of arthritis, had an impact on art and craft participation. One woman explained how a stroke had affected her ability to make three dimensional cards:

“I had a stroke earlier in the year. I'm a little bit weak in the hands. You've got to have a steady hand. It's no good putting a little fine propeller on an aeroplane if it's not in the right place.”

Various beliefs were expressed regarding the effects of art and craft activities on health. One woman had found that handling wet clay made her arthritis worse and so 
had discontinued this activity. Others believed art and craft activities helped keep their hands and bodies moving and attributed participation to improvements in cognitive abilities including memory and concentration:

“You need to have something to keep your brain active because it’s so easy for your brain to just deteriorate if you're not using it all the time”.

Various strategies were adopted to minimise the impact of physical ailments so that participation could continue. These strategies included limiting time spent on an activity; using the left hand instead of the right; using thick yarn instead of fine yarn; using thicker needles; restricting use of colour; using devices such as magnifying glasses; and changing to less technically demanding activities:

“My eyes aren’t as good as they used to be. I’ve got glaucoma of one eye and I've got macular degeneration looming up. It's quite bad really, so I think my embroidery days are a bit limited. Magnifying glasses help a bit but I think I’ll be doing less and less intricate work. I'll probably be resorting to something I can see easier, like doing tapestry with wool. I don’t want to have to give it up, but I suppose there will come a time when I will”.

\section{Developing a self view as enabled}

Through the act of making and by working within the contexts of participation, women developed a self view as enabled. They described feeling "confident” and considered participation as beneficial to their psychological well-being. By entering into the realm of "making”, the women were able to focus on activities which gave them joy and satisfaction. Some described these activities as "therapy" and as a diversion from their everyday worries: 
“It (weaving) takes my mind off my problems. At the moment I've got a husband who's in a dementia ward and sometimes I get very down thinking about him and when I get a bit miserable I go to my loom and do a bit of weaving and that takes my mind off that. I get the satisfaction of looking at something that's been made and I get the satisfaction of giving it to people. It is good therapy”.

Conversely, women who were unable to continue their art and craft interests described a process of dis-enablement, where they keenly felt the loss of these activities from their lives and had lost motivation and personal “energy”. Some specifically referred to the impact on their mental health:

“Now have macular degeneration. Cannot see to do all the things I love knitting, tapestry, sewing and many more things. Am struggling with depression as a result of my difficulties”.

Two concepts critical to developing a self view as enabled were "purpose" and what the authors have termed the "control continuum”. Women set goals for what they would make, decided how they would make it and for whom the item was made. They talked about "projects”, often in relation to charitable organisations which gave them specific reasons for making specific items. They derived pleasure from helping others: "I always have a project on the go, embroidery and patchwork. These things keep me from feeling old although I know I am old at 86”.

Art and craft activities also provided reasons to continue their own education and self development, looking forward: 
“I’m hoping to find a class next year to go a bit further and see how to do these things. You can buy books, but it's a little bit hard unless it's demonstrated to you”.

The women identified with particular activities, describing themselves as a "painter", an "artist", or a "knitter" and saw these activities as intrinsic to their own natures:

"I think it's something that's in you".

The outputs of these activities were also evidence of their capabilities and productivity:

“They (the paintings) made me feel I could do something. I wasn’t absolutely dumb”.

The women's artistic identities and outputs were also recognised and appreciated by others, contributing to the quality of their social relationships. One woman explained the response from a friend regarding a portrait she had painted for his birthday:

"He was amazingly happy. He made a nice frame and the picture is on the wall and everybody admires it, including me and including our friends”.

Important to conceptualising older women's participation in art and craft activities was the "control continuum". Control operated on a continuum from being fully in control of the act of making and the contexts of participation through to not being in control (and not trying to control) these processes at all. Women worked with the materials in hand and within the circumstances of their lives, weighing up the effort required for the outcomes to be achieved. While being fully in control was important 
and the desire for control was a motivator for ongoing learning and skill development, in the experimental realm of "making" the women came to appreciate the opportunity of being "out of control” and that this state was not something to be feared:

“Once you begin to paint, to really paint, it’s something you can’t stop”.

Control was subtle, neither too little nor too much. Indeed, lesser degrees of control could be more appropriate than greater degrees of control depending on the specific circumstances. A woman who spun wool described the nuanced nature of control as applied to the act of making. When she first began to spin she tried to force the materials to do what she wanted them to do and became "frustrated" to the point of crying. It was only when she gave up trying to dominate the materials, "just letting the wool go through your fingers" that she found the "knack". Then, it was "really, really relaxing”.

Older women's participation in art and craft activities: a conceptual model $<$ Insert Figure 1 about here $>$

Figure 1 represents a conceptual model regarding older women’s participation in art and craft activities. Central to the model is the act of making comprising cognitive and physical processes (thinking, sensing, manipulating) infused with emotion. When making, women enter "another world all of your own” and "away from the normal household chores” where their "energies" and "efforts" can be focused on "something you enjoy doing”. Social relationships, physical spaces, physical ailments and beliefs about the value of participation are important contexts of participation, which interact with one another and singly or together, can facilitate or hinder older women's participation in art and raft activities. Through participation, women find purpose in 
their lives, contributing to their own psychological well-being while helping and being appreciated by others. They come to understand the nuanced nature of control and learn to live with uncertainty. They develop a self view as able to do - "I could do that”, and as such take on new art and craft challenges, continuing to learn and develop as art and craft makers and being open to new possibilities.

\section{Discussion}

The concept of control has previously been presented as a dichotomy, with its presence understood as adaptive and health promoting while its absence has been understood as maladaptive and detrimental to health (Skaff, 2007). The findings from the current study suggest control operates in more complex ways, on a continuum, where control varies depending on the particular task, particular situation and context, and particular individual involved. Participation in art and craft activities facilitated this more nuanced understanding of control, where, in late life, women drew upon their life experience in general and their specific knowledge and skills in art and craft, to determine courses of action which included letting go of control. Understanding and applying control as a continuum, is a skill which would be potentially relevant to other areas of life beyond art and craft activities, and may represent what has been described as “emerging competencies inherent” in ageing (Golub and Langer, 2007, p.24). Instead of late life being a developmental challenge focusing on loss, late life is an opportunity to let whatever happens happen and focus energy on specific domains of interest and on the specific relationships of most importance. As future time is short, satisfying emotional and social goals become particularly salient in late life, as these goals can be realised in the immediate present, in contrast to knowledge goals that may take years to realise (Carstensen, Pasupathi, Mayr and Nesselroad, 2000). 
In attempting to understand positive well-being, two long standing philosophical traditions exist, that of eudaimonia and hedonism (Robinson, Kennedy and Harmon, 2012; Ryan and Deci, 2001). Eudaimonia concerns the fulfilment of human potential through purposeful actions consistent with a person's inner values and nature (Robinson et al., 2012) while hedonism is concerned with the "subjective experience of pleasure” (Robinson et al., 2012, p.151) and the pursuit of "happiness” (Ryan and Deci, 2001, p.148). Participation in art and craft activities encompassed these dual aspects of well-being, purpose and pleasure. Art and craft activities were personally meaningful, consistent with the women's inner natures and allowed them to help others and be useful, while at the same time, these activities appealed to the senses and satisfied the emotions. Studies on volunteering by older people have similarly identified both “altruistic” and “egotistic” motivations (Narushima, 2005, p.571) where "social contribution” and “self growth” are equally valued (Narushima, 2005, p.580).

Emotions are integral to health and are indicators of an individual's assessment of the "relevance and valence and events and conditions of life with respect to the self" (Ryan and Deci, 2001, p.147). With ageing there appears to be a shift towards the expression of positive emotions, with older adults better able to "regulate" emotions by appreciating the role of positive and negative emotions in the experience of living - described as “emotional complexity” (Davis, Zautra, Johnson, Murray and Okvat, 2007, p.252). Participation in art and craft activities offered a range of emotional experiences that may have served to enlarge the emotional repertoire of women involved in these activities, allowing them to make mistakes, accept frustrations and 
difficulties, and continue to learn as part of the process, thereby contributing to their own psychological well-being. Being able to respond to the challenges of changing physical capacities and illness and changing circumstances and relationships further re-enforced the women's own self concept as enabled women fully participating in the world around them. Others have proposed that the subjective view of being active, that is, responding on one's own terms, to changing conditions that "challenge the capacity to be active”, is critical to ageing well rather than participation per se (Stenner, McFarquhar and Bowling, 2010, p.474).

In conceptualising the complex links between participation and well-being, the nature of art and craft activities as well as the context of those activities, are important elements in the conceptual model. The act of making an art or craft item involves a coming together of mind, body and emotions to create something of meaning to the individual. This action is intimately connected to the individual's present circumstances and relationships while at the same time, draws upon past experiences and relationships. In "reconceptualising” gerontological theory around activity participation, Adams et al., (2011) have similarly regarded “content and context” of activity as well as how the individual appraises that activity in terms of "choice", “value” and “meaning” as being particularly significant in regard to well-being (Adams et al., 2011, p.707).

The study had several limitations. Firstly, it could be argued that as the open text comments and the interview transcripts represented different data sources and were collected at different times, they should have been analysed and presented separately. This would have been possible with the interview data however the open text 
comments were not conducive to a separate analysis as they provided limited data to allow conceptualisation and there was no possibility for clarification of what had been written. While the open text comments could not stand alone, they did provide data which complemented the interview transcripts and did contribute to the overall analysis. Secondly, nonverbal cues are lost in telephone interviews with the potential for less meaningful data than that obtained through face-to-face interviews, however research evidence to date does not indicate telephone interviews are inferior, and do offer advantages over face-to-face interviews, such as allowing access to participants otherwise unavailable due to geographical distance or personal circumstances and commitments (Novick, 2008). The telephone interviews were also relatively short, lasting up to 60 minutes. It could be argued that this was not sufficient time to fully explore the topics under consideration with each individual. However, considering all the data obtained from both open text comments and interview transcripts, saturation of concepts, their properties and dimensions had occurred with no additional concepts identified (Corbin and Strauss, 2008). An additional limitation of the study was that no detail was available about cultural background as an element of either the sociodemographic characteristics of participants in the study or more importantly how art and craft activities were linked into culture and social-cultural relationships.

The findings of the current study offer evidence that late life can be productive, meaningful and pleasurable, all of which are important for health and well-being. Through art and craft activities, older women learnt valuable lessons regarding the extent of control that is possible and desirable. They had purpose, were challenged and stimulated and remained open to opportunities for self development and self expression. They identified with their art and craft and connected with others through 
their art and craft, continuing to contribute to their families and communities and being recognised for their contributions. These findings echo those of Reynolds (2010) who similarly highlighted the benefits to well-being of arts participation as relating to both an enrichment of the self as well as the connection to others. Future research could explore the wider application of the conceptual model to understanding participation in art-making activities in late life among other population groups particularly men and people from diverse cultural backgrounds. While the conceptual model may be found to have application to other forms of participation beyond art and craft activities, the potentially unique characteristics of art-making that contribute to health and well-being are worth keeping to the fore in any future investigations.

\section{Conclusion}

Theoretical understandings of how art and craft activities, as a specific form of activity participation, relate to individual health and well-being in late life have been limited. Findings from the current study show that in the act of making an art or craft item, women enter a realm where it is possible to experiment and be open to new possibilities. Despite functional limitations and chronic disease, in this space away from everyday life, older women find purpose, consistent with their own natures and interests, and experience pleasure. The fourth age has been characterised as a difficult and dangerous time when "incompleteness" of bodily and mental functions and loss of social relationships come to the fore (Baltes and Smith, 2003, p.125). For women in late life, participation in art and craft activities may act as a psychological antidote to these stresses by offering a symbolic wholeness, where it is possible to complete items, help others, be valued and enjoy the moment. 


\section{Acknowledgements}

The research on which this paper is based was conducted as part of the Australian Longitudinal Study on Women's Health, the University of Newcastle and the University of Queensland. We are grateful to the Australian Government Department of Health and Ageing (DoHA) for funding and to the women who provided survey data and/or participated in the interviews. DoHA had no role in the study design, conduct, analysis and interpretation of data, presentation of the study findings or decision to submit this paper for publication. The research formed part of the first author's doctoral studies, which were supported by an Australian Postgraduate Award from the University of Newcastle.

\section{References}

Adams, K., Leibbrandt, S. \& Moon, H. (2011). A critical review of the literature on social and leisure activity and wellbeing in later life. Ageing and Society, 31, 683-712.

Adams-Price, C. (Ed.). (1998). Creativity and successful aging: theoretical and empirical approaches. New York: Springer.

Adamson, L. \& Parker, G. (2006). “There’s more to life than just walking”: older women's ways of staying healthy and happy. Journal of Aging and Physical Activity, 14, 380-91.

Agahi, N. \& Parker, M.G. (2008). Leisure activities and mortality: does gender matter? Journal of Aging and Health, 20(7), 855-871.

Australian Bureau of Statistics. (2006). Population by age and sex, Australian States and Territories. Australian Bureau of Statistics. Available online at 
http://www.abs.gov.au/AUSSTATS/abs@nsf/DetailsPage/ [Accessed 3 July 2009].

Baltes, P.B \& Baltes, M.M. (1990). Successful aging: perspectives from the behavioral sciences. New York: Cambridge University Press.

Baltes, P. B. \& Smith, J. (2003). New frontiers in the future of aging: from successful aging of the young old to the dilemmas of the fourth age. Gerontology, 49(2), 123-135.

Boudiny, K. (2012). ‘Active ageing’: from empty rhetoric to effective policy tool. Ageing and Society, Advanced online publication, available on CJO doi:10.1017/S0144686X1200030X.

Bryant, L. L., Corbett, K. K. \& Kutner, J. S. (2001). In their own words: a model of healthy aging. Social Science \& Medicine, 53, 927-941.

Burt, E. L. \& Atkinson, J. (2012). The relationship between quilting and wellbeing. Journal of Public Health, 34(1), 54-59.

Carstensen, L.L., Pasupathi, M., Mayr, U. \& Nesselroad, J.R. (2000). Emotional experience in everyday life across the adult life span. Journal of Personality and Social Psychology, 79 (4), 644-655.

Cheek, C. \& Piercy, K.W. (2004). Quilting as age identity expression in traditional women. International Journal of Aging and Human Development, 59(4), 321337.

Corbin, J. \& Strauss, A. (2008). Basics of qualitative research. Techniques and procedures for developing grounded theory. ( $3^{\text {rd }}$ edition). Los Angeles, CA: SAGE Publications.

Crosnoe, R. \& Elder Jr., G. H. (2002). Successful adaptation in the later years: a life course approach to aging. Social Psychology Quarterly, 65(4), 309-328. 
Csikszentmihalyi, M. (1996). Creativity: flow and the psychology of discovery and invention. New York: HarperCollins Publishers.

Davis, M.C., Zautra, A.J., Johnson, L.M., Murray, K.E. \& Okvat, H.A. (2007). Psychosocial stress, emotion regulation and resilience among older adults. In C. M. Aldwin, C. L. Park and A. Spiro (eds.), Handbook of Health Psychology and Aging, Guildford Press, New York, 250-66.

Depp, C.A., \& Jeste, D.V. (2006). Definitions and predictors of successful aging: a comprehensive review of larger quantitative studies. The American Journal of Geriatric Psychiatry, 14(1), 6-20.

Dickie, V. A. (2003). The role of learning in quilt making. Journal of Occupational Science, 10(3), 120-129.

Dissanayake, E. (1988). What is Art For? Seattle: University of Washington Press.

Forssén, A.S. (2007). Humour, beauty, and culture as personal health resources: experiences of elderly Swedish women. Scandinavian Journal of Public Health, 35, 228-234.

Fisher B.J \& Specht D.K. (1999). Successful aging and creativity in later life. Journal of Aging Studies, 13(4), 457-472.

Galloway, S. 2(006). Cultural participation and individual quality of life: a review of research findings. Applied Research in Quality of Life, 1, 323-342.

Glatt, S. J., Chayavichitsilp, P., Depp, C., Schork, N. J. \& Jeste, D.V. (2007). Successful aging: from phenotype to genotype. Biological Psychiatry, 62, 282293.

Golub, S. A. \& Langer, E. J. (2007). Challenging assumptions about adult development. Implications for the health of older adults. In C.M. Aldwin, C. 
L. Park \& A. Spiro (Eds.), Handbook of health psychology and aging (pp.929). New York: Guildford Press.

Greaves, C. J. \& Farbus, L. (2006). Effects of creative and social activity on the health and well-being of socially isolated older people: outcomes from a multi-method observational study. The Journal of the Royal Society for the Promotion of Health, 126 (3), 134-142.

Hacking, S., Secker, J., Kent, L., Shenton, J. \& Spandler, H. (2006). Mental health and arts participation: the state of the art in England. The Journal of the Royal Society for the Promotion of Health, 126(3), 121-127.

Häggblom-Kronlöf, G. \& Sonn, U. (2005). Interests that occupy 86-year-old persons living at home: associations with functional ability, self-rated health and sociodemographic characteristics. Australian Occupational Therapy Journal, 53, 196-204.

Howie, L., Coulter, M. \& Feldman, S. (2004). Crafting the self: older persons’ narratives of occupational identity. American Journal of Occupational Therapy, 58, 446-454.

Hughes, T. F., Chang, C.-C. H., Vander Bilt, J. \& Ganguli, M. (2010). Engagement in reading and hobbies and risk of incident dementia: the MoVIES project. American Journal of Alzheimer's Disease and Other Dementias, 25(5), 432438.

Johnson, J.S. \& Wilson, L.E. (2005). "It says you really care": motivational factors of contemporary female handcrafters. Clothing \& Textiles Research Journal, 23(2), $115-130$. 
Lemon, B.W., Bengston, V.L. \& Peterson, J.A. (1972). An exploration of the activity theory of aging: activity types and life satisfaction among in-movers to a retirement community. Journal of Gerontology, 27(4), 511-523.

Lloyd, L., Calnan, M., Cameron, A., Seymour, J. \& Smith, R. (2012). Identity in the fourth age: perseverance, adaptation and maintaining dignity. Ageing and Society, Advanced online publication available on CJO doi:10.1017/S0144686X12000761.

Maslow, A. H. (1968). Toward a psychology of being. ( $2^{\text {nd }}$ Edition). New York: D. Van Nostrand Company.

Maslow, A. H. (1976). Religions, values, and peak-experiences. Harmondsworth, England: Penguin Books.

Menec, V. H. (2003). The relation between everyday activities and successful aging: a 6-year longitudinal study. Journal of Gerontology: Social Sciences, 58B, S7482.

Montross, L.P., Depp, C., Daly, J., Reichstadt, J., Golshan, S., Moore, D., Sitzer, D. \& Jeste, D.V. (2006). Correlates of self-rated successful aging among community-dwelling older adults. American Journal of Geriatric Psychiatry, 14(1), 43-51.

Morse, J., Noerager Stern, P., Corbin, J., Bowers, B., Charmaz, K. \& Clarke, A. (2009). Developing grounded theory. The second generation. Walnut Creek, CA.: Left Coast Press, Inc..

Narushima, M. (2005). 'Payback time’: community volunteering among older adults as a transformative mechanism. Ageing and Society, 25(4), 567-584.

Novick, G. (2008). Is there a bias against telephone interviews in qualitative research? Research in Nursing and Health, 31(4), 391-398. 
O'Shea, E. \& Léime, A. (2012). The impact of the Bealtaine arts programme on the quality of life, wellbeing and social interaction of older people in Ireland. Ageing and Society, 32, 851-872.

Phelan, E.A., Anderson, L.A., LaCroix, A.Z. \& Larson, E.B. (2004). Older adults’ views of “'successful aging”'- how do they compare with researchers' definitions? Journal of the American Geriatrics Society, 52, 211-216.

Piercy, K. W. \& Cheek, C. (2004). Tending and befriending: the intertwined relationships of quilters. Journal of Women \& Aging, 16(1/2), 17-33.

Putland, C. (2008). Lost in translation: the question of evidence linking communitybased Arts and health promotion. Journal of Health Psychology, 13(2), 265276.

Raw, A., Lewis, S., Russell, A. \& Macnaughton, J. (2012). A hole in the heart: confronting the drive for evidence-based impact research in arts and health. Arts \& Health: An International Journal for Research, Policy and Practice, 4(2), 97-108.

Reynolds, F. (2009). Taking up arts and crafts in later life: a qualitative study of the experiential factors that encourage participation in creative activities. British Journal of Occupational Therapy, 72(9), 393-400.

Reynolds, F. (2010). “Colour and communion”: exploring the influences of visual artmaking as a leisure activity on older women's subjective well-being. Journal of Aging Studies, 24, 135-143.

Reynolds, F. \& Lim, K. H. (2007). Contribution of visual art-making to the subjective well-being of women living with cancer: a qualitative study. The Arts in Psychotherapy, 34, 1-10. 
Robinson, K., Kennedy, N. \& Harmon, D. (2012). Happiness: a review of evidence relevant to occupational science. Journal of Occupational Science, 19(2), 150164.

Runco, M. A. (2007). Creativity theories and themes: research, development and practice. Burlington, MA.: Elsevier Academic Press.

Ryan, R.M. \& Deci, E.L. (2001). On happiness and human potentials: a review of research on hedonic and eudaimonic well-being. Annual Review of Psychology, 52, 141-166.

Schofield-Tomschin, S. \& Littrell, M.A. (2001). Textile handcraft guild participation: a conduit to successful aging. Clothing and Textiles Research Journal, 19(2), $41-51$.

Silverstein, M. \& Parker, M.G. (2002). Leisure activities and quality of life among the oldest old in Sweden. Research on Aging, 24, 528-547.

Skaff, M. M. (2007). Sense of control and health. A dynamic duo in the aging process. In C. M. Aldwin, C. L. Park \& A. Spiro (Eds.), Handbook of Health Psychology and Aging (pp.186-209). New York: Guildford Press.

Stenner, P., McFarquhar, T. \& Bowling, A. (2011). Older people and 'active ageing': subjective aspects of ageing actively. Journal of Health Psychology, 16(3), 467-477.

Stickley, T. \& Duncan, K. (2007). Art in Mind: implementation of a community arts initiative to promote mental health. Journal of Public Mental Health, 6(4), 2432.

United Nations. (2008). The Madrid international plan of action on ageing. Guiding framework and toolkit for practitioners \& policy makers. United Nations Department of Economic \& Social Affairs Division for Social Policy \& 
Development. Available online at

www.un.org/ageing/documents/building_natl_capacity/guiding.pdf [Accessed 29 May 2012].

Women's Health Australia. (2011). Australian longitudinal study on women's health. Newcastle, NSW: Women’s Health Australia.

World Health Organization. (2002). Ageing. World Health Organization. Available online at http://who.int/ageing/en/index.html [Accessed 3 July 2009].

Wreford, G. (2010). The state of arts and health in Australia. Arts \& Health: An International Journal for Research, Policy and Practice, 2(1), 8-22. 


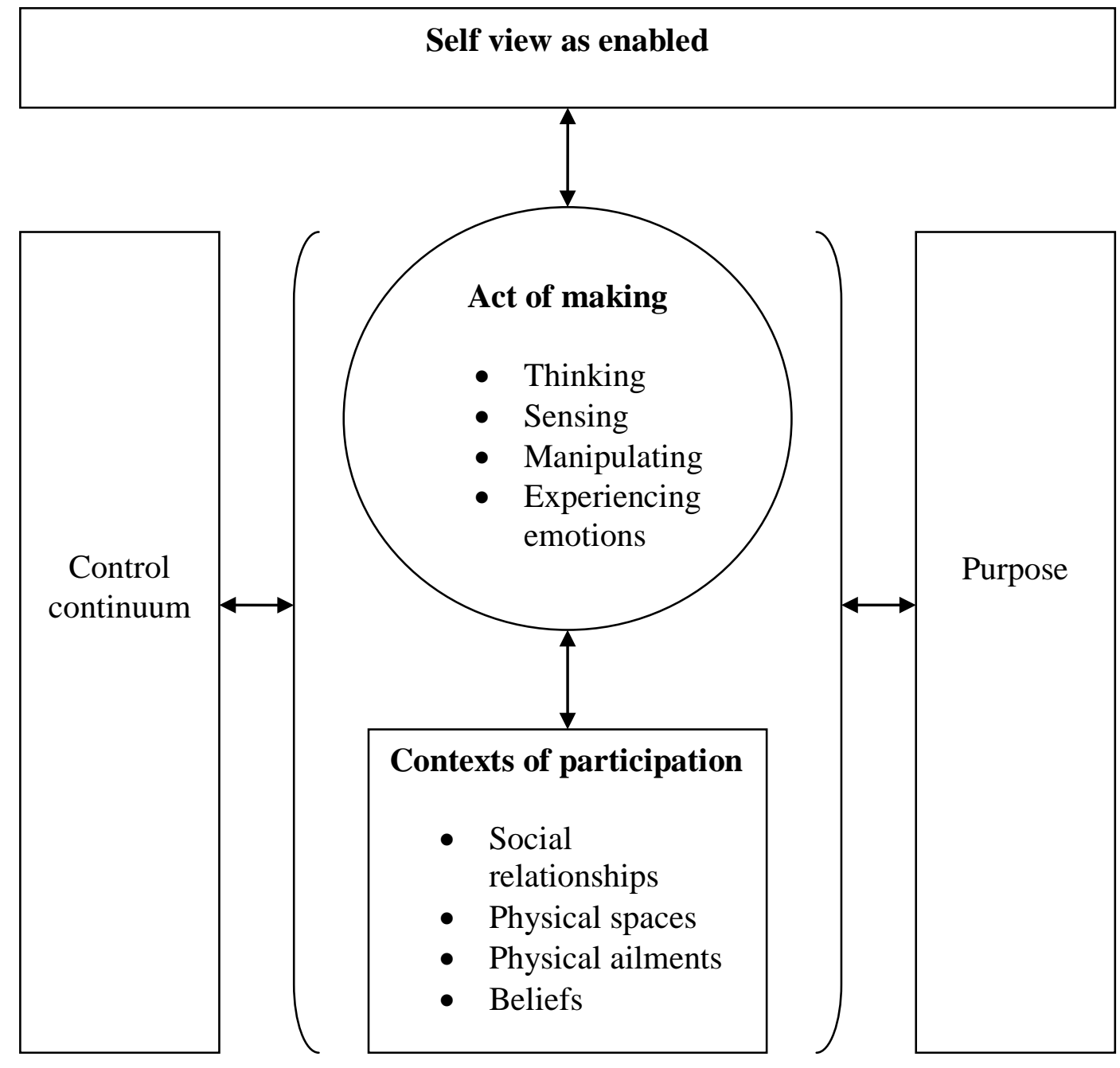

